University of Louisville

ThinkIR: The University of Louisville's Institutional Repository

$5-2018$

\title{
Effect of porcelain thickness and translucency on the final shade of IPS e.max CAD overlaying a dark substrate.
}

Peter F. Alena

University of Louisville

Follow this and additional works at: https://ir.library.louisville.edu/etd

Part of the Dental Materials Commons

\section{Recommended Citation}

Alena, Peter F., "Effect of porcelain thickness and translucency on the final shade of IPS e.max CAD overlaying a dark substrate." (2018). Electronic Theses and Dissertations. Paper 2912.

https://doi.org/10.18297/etd/2912

This Master's Thesis is brought to you for free and open access by ThinkIR: The University of Louisville's Institutional Repository. It has been accepted for inclusion in Electronic Theses and Dissertations by an authorized administrator of ThinkIR: The University of Louisville's Institutional Repository. This title appears here courtesy of the author, who has retained all other copyrights. For more information, please contact thinkir@louisville.edu. 
EFFECT OF PORCELAIN THICKNESS AND TRANSLUCENCY ON THE FINAL SHADE OF IPS E.MAX CAD OVERLAYING A DARK SUBSTRATE

\author{
By \\ Peter F. Alena \\ B.S. University of Georgia, 2013 \\ A Thesis \\ Submitted to the Faculty of \\ The University of Louisville School of Dentistry \\ For the degree of \\ Master of Science \\ in Oral Biology \\ Department of General Dentistry and Oral Medicine \\ University of Louisville \\ Louisville, KY
}

May 2018 

EFFECT OF PORCELAIN THICKNESS AND TRANSLUCENCY ON THE FINAL SHADE OF IPS E.MAX CAD OVERLAYING A DARK SUBSTRATE

\title{
By
}

\author{
Peter F. Alena \\ B.S. University of Georgia, 2013 \\ A Thesis Approved on \\ May 08, 2018 \\ by the following Thesis Committee: \\ Marcelo Durski, DDS, PhD, MS Mentor \\ Michael Metz, DMD, MSD, MS, PhD, Committee Member \\ Gary Crim, DMD, Committee Member
}




\section{DEDICATION}

I dedicate this thesis to my father, Dr. Frank Alena, who has always shown me the value of curiosity, resilience, and seizing opportunities in hopes of developing a brighter future. 


\section{ACKNOWLEDGEMENTS}

I would like to acknowledge Ivoclar Vivadent for generously donating the materials necessary to conduct this study.

I would also like to sincerely thank my research mentor, Dr. Marcelo Durski, for his experience, guidance, and patience, which all enabled me to successfully complete this project. By researching dental materials, I found a great friend. 


\begin{abstract}
EFFECT OF PORCELAIN THICKNESS AND TRANSLUCENCY ON THE FINAL SHADE OF IPS E.MAX CAD OVERLAYING A DARK SUBSTRATE
\end{abstract}

Peter F. Alena

May 08, 2018

IPS e.max is a very esthetic lithium disilicate used in dental ceramics. Unfortunately, it can unintentionally change color after cementation with resin cements. The purpose of this study is to better understand how combining thickness and translucency affects the post-cementation shade of IPS e.max CAD overlaying a dark substrate, thereby enabling clinicians to choose more appropriate techniques and materials. IPS e.max CADs (A1 shade) had either a low translucency (LT) or high translucency (HT), and cut with $0.3 \mathrm{~mm}, 0.5 \mathrm{~mm}$, and $1.0 \mathrm{~mm}$ thicknesses. Each sample overlaid a resin cement and dark substrate, a spectrophotometer helped derive the color difference $\left(\Delta E^{*} a\right)$, and a 2-way ANOVA $(p<.0001)$ and Tukey's HSD test $(\alpha=.05)$ determined the significance. The $\Delta \mathrm{E}^{*}$ ab was significantly dependent on both the translucency and thickness. Overall, as the thickness increased, and the translucency decreased, lower mean $\Delta \mathrm{E}^{*}$ ab values were observed. However, all groups presented clinically unacceptable $(\Delta \mathrm{E}>3.3)$ shade changes. 


\section{TABLE OF CONTENTS}

\section{PAGE}

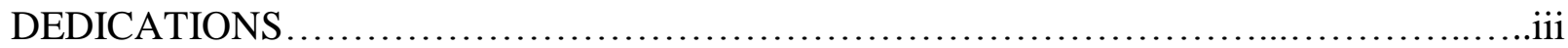

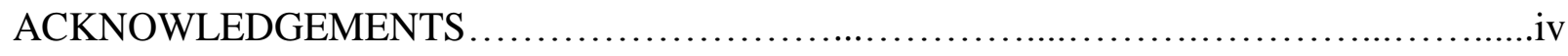

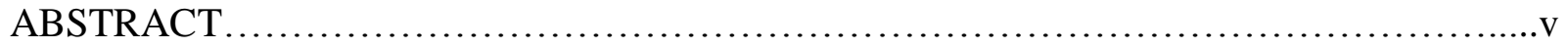

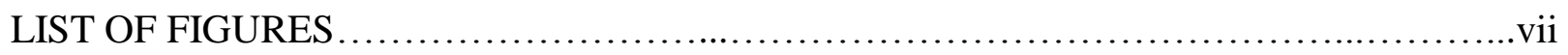

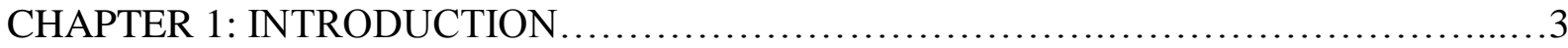

CHAPTER 2: MATERIALS AND METHODS ........................................

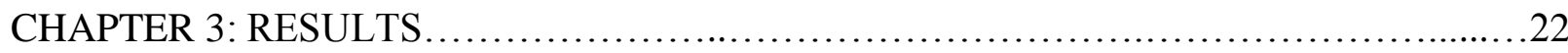

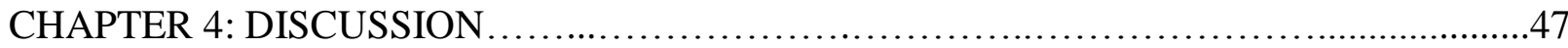

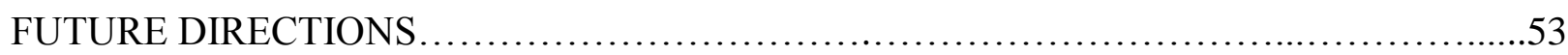

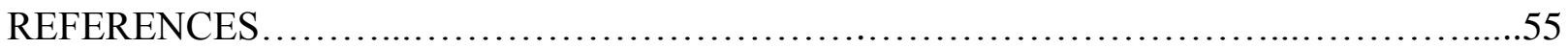

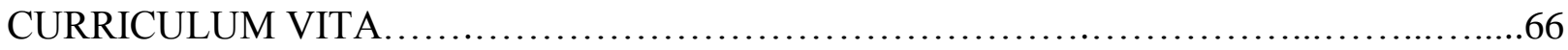




\section{LIST OF FIGURES}

PAGE

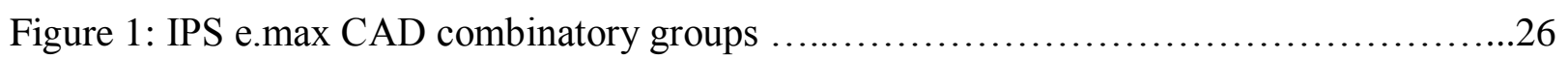

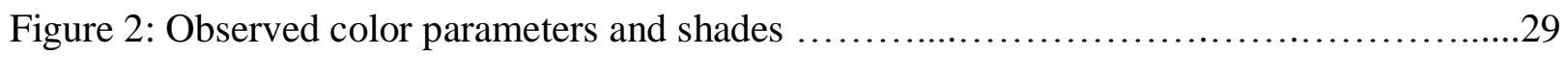

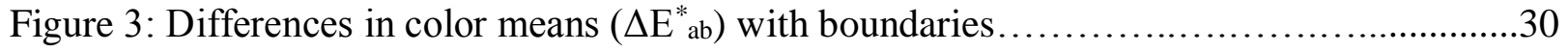

Figure 4: Difference in color means $\left(\Delta \mathrm{E}^{*}{ }_{\mathrm{ab}}\right)$ with standard error bars $\ldots \ldots \ldots \ldots \ldots \ldots \ldots \ldots \ldots \ldots \ldots \ldots \ldots \ldots \ldots$ 


\section{CHAPTER 1}

\section{INTRODUCTION}

\section{History and Significance of Glass-Ceramics}

Fabricating a restoration that is esthetically acceptable when compared to the adjacent dentition continues to be a significant challenge for restorative dentists. Many factors and conditions must be taken into consideration in order to create a fixed prosthesis that will satisfy the most esthetically conscious patients. Since the advent of ceramic usage in dentistry dating back to the early 1940's, the materials and techniques used to restore oral form and function have revolutionized. In the mid-1960s, McLean came out with the aluminum reinforced porcelain jacket crown (McLean, 1967). By the mid-1980s, the probability of an anterior porcelain jacket failing within an 11 year time frame was $25 \%$, with an even higher percentage in the posterior zone (Leempoel, Eschen, De Haan, \& Van't Hof, 1985). However, in 1983 the works of Horn, Simonsen, and Calamia unveiled the acid-etched ceramic, which ultimately transformed the way ceramics were viewed in the dental community (Calamia, 1983; Horn, 1983; Simonsen RJ. \& Calamia JR., 1983). The early 1990s brought dentin adhesives that increased the bond strength between luting agents and all-ceramic restorations (Pospiech, 2002). This system allowed practitioners to start avoiding metal-ceramic crowns in the esthetic zone, which had previously been doctrine. Around the same time, Ivoclar Vivadent unveiled the IPS Empress 1, which was a "glass-ceramic" reinforced by leucite intricately dispersed within an amorphous glass matrix, 
thereby making it esthetic yet more resistant to cracking. IPS Empress 1 was ultimately succeeded by the glass-ceramic IPS Empress 2, which contained a more visually appealing lithium disilicate (S. Kang, Chang, \& Son, 2013). Ivoclar Vivadent released the IPS e.max Press in 2001, allowing lab technicians to enhance both the optical and mechanical properties of the lithium disilicate ceramics. In 2005, IPS e.max CAD became available which allowed clinicians the ability to start incorporating CAD/CAM with their lithium disilicate restorations (S. Kang et al., 2013) Patients and practitioners alike can now appreciate the use of porcelain restorations in situations involving the correction of tooth forms/position, discoloration, diastemas, erosion, abrasion, etc. (Friedman, 2001).

Advantages of using ceramic over the traditional metal substructures include increased light transmission in esthetic cases, ability to have supragingival margins, better emergence profiles, and decreased plaque adherence. Glass-ceramic materials also demonstrate improved retention when localized to enamel due to their internally etched surface with hydrofluoric acid and a silane-coupling agent (da Cunha et al., 2013). Even though they possess good mechanical properties, metal substructures have the potential to cause gingival shadowing, allergic reactions, and the release of metallic ions into gingival crevicular fluids (Shenoy \& Shenoy, 2010). A ceramic restoration without a metal substructure also allows for a greater amount of light transmission, along with the potential for better translucency and color (O. Ozturk, Uludag, Usumez, Sahin, \& Celik, 2008). However, previous studies done on the discoloring effects of a dark abutment have shown that fabricating ceramic restorations with thicknesses of $2.0 \mathrm{~mm}$ or greater have the best chance at masking the underlying tooth shade. Yet it is often unreasonable or disadvantageous to reduce a tooth to this "ideal" amount since pulpal health or restorability may be compromised in place of esthetics (Niu, Agustin, \& Douglas, 2014). Irreversible pulpitis 
can become a concern when $63-73 \%$ of tooth structure is typically removed during traditional crown preparations (Tariq F. Alghazzawi, Lemons, Liu, Essig, \& Janowski, 2012). But with acid etching, ceramics can be predictably and conservatively cemented without the need to reduce 1.0-1.5mm of tooth structure to produce a retentive ferule (Friedman, 2001). Regarding longevity, a retrospective clinical study spanning 20 years estimated the probability of porcelain veneers surviving 5 years $(94.4 \%), 8$ years $(94.1 \%), 10$ years $(93.5 \%), 15$ years $(85.74 \%)$, and 20 years (82.93\%) (Beier, Kapferer, Burtscher, \& Dumfahrt, 2012). Porcelain laminate veneers (PLV) can provide impressive optical properties, color stability, and ultimately a suitable alternative to traditional full coverage, all-ceramic crowns when properly indicated (Friedman, 2001).

However, porcelain laminate veneers do not go without complications. Clinicians reported porcelain fractures as the primary cause of failure of their veneers (Peumans, Van Meerbeek, Lambrechts, \& Vanherle, 2000), followed by cracks within the veneer ceramic, chipping, and debonding (Beier et al., 2012). Ceramics have the ability to form both ionic and covalent bonds that contribute to increased compressive strength, but they still tend to be brittle and lack tensile strength (Giordano \& McLaren, 2010). Porcelain laminate veneers are also more likely to be discolored when bonded to non-vital teeth, fractured in patients with bruxism (Peumans et al., 2000) and have marginal staining in smokers (Beier et al., 2012). Therefore, a restorative dentist should be knowledgeable of each individual patient's oral condition and esthetic demands so that decisions between porcelain laminate veneers, resin composite veneers, or all-ceramic crowns can be made appropriately (da Cunha et al., 2013).

Types and Compositions of Ceramics 
Dental ceramics can theoretically be considered as "composites" since they are distinctly formed by two or more components/fillers, but ceramics are markedly different from the resin composites frequently used in direct restorative situations. Organizing ceramics based on the type, amount, fabrication methods, and reason for adding filler particles can greatly help in understanding when the ceramic is best utilized (Kelly, 2004). Technically speaking, all ceramics contain a crystalline microstructure; therefore, the term "porcelain" represents a ceramic partially combined with a glassy/non-crystalline component (Giordano \& McLaren, 2010). Dental ceramics can be generally classified by their microstructure and the processing technique used for fabrication (Giordano \& McLaren, 2010; Shenoy \& Shenoy, 2010). The microstructure of dental ceramics is divided into three broad categories: predominantly glassy, particle-filled glasses, and polycrystalline (Kelly, 2004).

Ceramics that are predominantly glassy resemble enamel's optical properties and are frequently incorporated into highly esthetic areas (Kelly, 2004). Glasses, which are 3-D atomic networks with no apparent organization of its components, are traditionally derived from mined feldspar. Feldspar is primarily made out of silicon oxide (silica) and aluminum oxide (alumina) that compose the aluminosilicate glass family (Kelly, 2004). Glasses have low flexural strength ( 65MPa) so they are often incorporated as veneering materials over stronger metal or crystalline substructures (Giordano \& McLaren, 2010).

The optical and mechanical properties of the glass can be manipulated by the addition of crystalline filler particles, thereby increasing the ceramic's strength and color/opacity. "Glassceramic" porcelains will then have a larger resistance to thermal shock, fracture, and erosion (Giordano \& McLaren, 2010). Leucite, lithium disilicate, and fluorapatite represent the different crystalline compositions of glass-ceramic restorations, and the observed optical properties of an 
esthetic restoration may be dependent on which material was chosen (Bagis \& Turgut, 2013). Leucite was the initial filler to be used in metal-ceramic restorations since it possesses a similar contraction/expansion coefficient as the metal substructure to which it is bound (Kelly, 2004). However, leucite was later adapted in glass-ceramic restorations by increasing the amount of potassium oxide in aluminosilicate glass (Giordano \& McLaren, 2010).

More recently, lithium disilicate has been uniquely used in glass-ceramics. Lithium disilicate was originally marketed by the Ivoclar Vivadent company as IPS Empress II and has since gained popularity due to its observed strength, chemical durability, abrasion pattern, and impressive esthetics (Giordano \& McLaren, 2010; Niu et al., 2014). Prior to undergoing heat treatment and becoming fully crystalized, it is comprised of two crystal nuclei, namely lithium disilicate and lithium metasilicate (Della Bona, Nogueira, \& Pecho, 2014). The crystalline lithium disilicate filler is added to a previously formed glass structure (prosthesis/pellet), which undergoes a special heat treatment called "creaming" that precipitates the crystallites to grow within the glass itself. Manipulating the crystallization heat treatment will change the crystal size and crystalline content of the ceramic to about $70 \%$, which creates a highly filled glassy matrix (Giordano \& McLaren, 2010). These alterations can all ultimately influence the perceived translucency.

Ceramics containing no glassy components (dense, systematic order of atoms) are considered to be polycrystalline (Kelly, 2004). These ceramics have a larger crystalline concentration with finer-sized crystals; therefore, they become stronger than their glassy counterparts. Propagating cracks are largely thwarted in highly crystalized ceramics since the crack must go around the crystals, which decreases their energy and progression (Giordano \& McLaren, 2010). Polycrystalline ceramics are also more noticeably opaque (O. Ozturk et al., 
2008), so they are more frequently used as higher strength substructures that have a glassy ceramic layered on top in order to maintain esthetic appeal when required (Kelly, 2004).

\section{IPS e.max $C A D$}

The material in question for this study is the IPS e.max CAD lithium disilicate, a category 2 glass-based system (Alkadi \& Ruse, 2016). According to the manufacturer, the IPS e.max CAD is available in five different forms, including low translucency, medium translucency, high translucency, high opacity, and an opalescent form (Ivoclar Vivadent, 2015, October). IPS e.max CAD is proprietarily sold by Ivoclar Vivadent and marketed in three different systems. IPS e.max CAD Monolithic Solutions is advertised for thin veneers, single unit crowns, and three unit bridges capable of withstanding increased forces $\geq 360 \mathrm{MPa}$. IPS e.max CAD Veneering Solutions contain a zirconium oxide framework that is overlaid with a digitally fabricated veneering ceramic. This esthetic product is better suited for high strength areas with tooth or implant-retained crowns and longer spanning bridges. IPS e.max CAD Abutment Solutions is designed for hybrid restorations supported by implants or single tooth crowns (Ivoclar Vivadent, 2015, October).

Currently there are five techniques utilized in the fabrication of all-ceramic restorations, which include condensation/sintering, casting/creaming, slip casting, pressing, and CAD/CAM. Along with the ceramic opacity and shade, the brand, batch, condensation technique, temperatures, numbers of firing, and thickness of dentin all factor into a fabricated restoration's ability to match the shade guide (O. Ozturk et al., 2008). According to manufacturer's recommendations, the IPS e.max CAD blocks should be milled using either Ivoclar Vivadent 
PrograMill One, CEREC (Sirona), or Planmeca FIT (E4D Technologies) (Ivoclar Vivadent, 2017). Initially, the ceramic block is composed of partially crystalized lithium disilicate, thereby enabling it to be designed and milled by CAD/CAM. Being partially crystalized also decreases the milling time as well as the incidence of chipping. A 20- to 30-minute heat-treatment follows the milling so that the glass becomes fully crystalized. Also, the restoration converts from a blue color to the final shade, and the mechanical properties are achieved (Giordano \& McLaren, 2010).

Many dentists are routinely incorporating CAD/CAM into their practices largely due to its convenience; both the dentist and patient are spared chair time with theoretically less appointments. Nevertheless, there is yet to be a formally established protocol when attempting porcelain restorations using CAD/CAM technology. During the restorative planning stage, diagnostic casts should be recorded in order to determine the future size/shape/color of teeth and the gingival contour (da Cunha, Mukai, Hamerschmitt, \& Correr, 2015). Clinicians should pay particular attention in selecting two shades, namely the desired shade of final restoration and the shade of the substrate or dentin (Sari et al., 2017). Total arch intraoral scans create a virtual model of the mouth so that the esthetics and functional parameters are considered in the restorative wax-up (da Cunha et al., 2015). Minimally invasive veneers are an appealing option when clinically appropriate, since they allow enamel to be persevered, particularly at the margin. After a thorough evaluation, rotary instruments with diamond burs should be used for the minimal thickness preparation. A gingival displacement cord should then be used to help expose the margins prior to taking a digital impression that will be sent to the CAM machine to fabricate the final restoration (da Cunha et al., 2015). 
Besides theoretically allowing a dentist to avoid fabricating a provisional restoration and instead a permanent ceramic restoration in a single appointment (Schmitter \& Seydler B, 2012; Vafiadis \& Goldstein, 2011), the use of CAD/CAM technologies can lead to more predictable thicknesses and ultimately a more predictable shade. A 5-year survival rate of $97 \%$ and a 10 -year survival rate of $90 \%$ have been reported for CEREC-fabricated restorations (Goujat et al., 2018). Newer technologies enable the CAD/CAM manufacturing of a ceramic coping that can be layered with both opaque and translucent porcelain (Dozic, Kleverlaan, Meegdes, van der Zel, \& Feilzer, 2003). Zirconia- and alumina-based ceramic cores often necessitate the addition of a fracture-prone porcelain layer in order to become esthetically pleasing (W. Kang, Park, Kim, Kim, \& Kim, 2018), but the monolithic IPS e.max porcelains inherently have impressive esthetics that can be further enhanced by simply adding an exterior stain (S. Kang et al., 2013).

\section{Optical Qualities and Spectrophotometers}

Matching human teeth with restorations proves challenging since tooth appearance and shade is an intricate process, involving translucency, opacity, fluorescence, surface texture, and lighting conditions (Begum, Chheda, Shruthi, \& Sonika, 2014; O. Ozturk et al., 2008; Uludag, Usumez, Sahin, Eser, \& Ercoban, 2007; Vichi, Louca, Corciolani, \& Ferrari, 2011). Hue, chroma, and value are all components of perceived color and can be individually quantified using a special type of spectrophotometer called a colorimeter (Ahn \& Lee, 2008). The Munsell color space describes hue as the difference between color families, chroma is the color saturation, and value is the color lightness (Park, Lee, \& Lim, 2006). Translucency is the amount of light transmitted or diffused through a substrate (Uludag et al., 2007). In other words, translucency can be considered the junction between total opacity and transparency (Della Bona 
et al., 2014), and needs to be carefully controlled in order to obtain a predictable outcome.

When attempting to shade match porcelain restorations, the color of the surrounding teeth is evaluated and traditionally described by the means of a defined code. The first shade guides introduced to the dental community in the 1950's were not based on scientific criteria or codes, but rather individual perceptions of color. Nevertheless, rationally arranged shade guides were quickly adopted by clinicians and addressed the pre-existing need for a color matching system (Vichi et al., 2011). Presently, the color code, or rather "shade tab," is used in dentistry as a shade matching standard that also defines accepted qualities and quantities of the porcelain powder used in fabricating restorations (Dozic, Tsagkari, Khashayar, \& Aboushelib, 2010).

Color science also proves to be full of complexities. The color observed from an unaided human eye is dependent on the illuminant's color characteristics, and the various angles between the illuminant, object, and eye. Metamerism occurs when the perceived color of an object under one illuminant changes when viewed under a different illuminant, which may further complicate the shade selection process. Additional subjectivity arises from the eye's previous conditions, specifically exposures, age, color blindness, or simply an individual's inherent color perception (Dozic, Kleverlaan, El-Zohairy, Feilzer, \& Khashayar, 2007; Kim-Pusateri, Brewer, Davis, \& Wee, 2009). A study done by Gomez-Polo et al. (2016) indicated that women are typically more sensitive in detecting color difference than their male counterparts. These subjectivities have often resulted in inconsistencies when using the Vita Classical shade guide; hence, the Vita 3DMaster shade guide was developed to make the shade selection process more convenient (Gomez-Polo, Gomez-Polo, Martinez Vazquez de Parga, \& Celemin-Vinuela, 2017). This 3DMaster color system incorporates 26 physical shade tabs, which homogenize colors along the chromatic spectrum. The value of a color is depicted by the first number, followed by the hue 
(letter), and ultimately the chroma (second number). Ultimately, it is believed that this system increases chromatic variation so a more accurate restorative shade may be selected (Gomez-Polo et al., 2017).

Alternative methods for testing shades include the use of colorimeters, which are proving to be a more objective, reliable alternative to traditional shade selection with visual tabs (Ishikawa-Nagai, Yoshida, Sakai, Kristiansen, \& Da Silva, 2009). In order for the quantitative measurements obtained by the colorimeters to have significance, the data must be compared to meaningful and established parameters. Two important factors must be determined in order to measure the esthetic success of a restoration. First, the value of the Euclidean distance $(\Delta \mathrm{E})$, or change in color, should define a perceptible difference in color (Ishikawa-Nagai et al., 2009). The $\Delta \mathrm{E}$ is used to mitigate discrepancies in color perception between different individuals (Bagis \& Turgut, 2013). Secondly, one must establish a threshold to determine if a color difference is acceptable or not. There is still debate regarding the perceptibility threshold (visually detectable color difference) and acceptability threshold (color difference that is clinically acceptable) (Ishikawa-Nagai et al., 2009).

Colorimeters incorporate color filters that approximate the color spectrum, and in this case reflect data according to the Commission Internationale de l'Eclairage. Major concepts in color science such as illumination patterns, color systems, and color difference $(\Delta \mathrm{E})$ are largely derived from this organization (Pecho, Ghinea, Alessandretti, Perez, \& Della Bona, 2016). Developed in 1978 and ultimately used in both dentistry and industry, the CIEL*a*b* standards use the three coordinates $\mathrm{L}^{*}, \mathrm{a}^{*}$, and $\mathrm{b}^{*}$ to quantify a perceptible color change of an object. The lightness of an object is represented by $\mathrm{L}^{*}$, while $\mathrm{a}^{*}$ represents redness (positive) or greenness (negative). The yellowness (positive) or blueness (negative) of an object is portrayed by $b^{*}$ 
(Vichi et al., 2011). Once these measurements are obtained, the color difference ( $\Delta \mathrm{E})$ between 2 objects can be calculated using the following equation:

$\Delta \mathrm{E}^{*}{ }_{\mathrm{ab}}=\left[\left(\Delta \mathrm{L}^{*}\right) 2+\left(\Delta \mathrm{a}^{*}\right) 2+\left(\Delta \mathrm{b}^{*}\right) 2\right] 1 / 2$

The $\Delta \mathrm{E}^{*}$ ab equation is viewed as the traditional, standard parameter used to determine color differences. Based on this CIEL*a*b* metric, a greater value (lightness) will indicate a larger color difference (Pecho, Ghinea, et al., 2016; Yuan, Brewer, Monaco, \& Davis, 2007). Esthetic restorations become noticeably flawed when the value is improperly managed. This unintended result is due to the human eye's heightened sensitivity to value, more so than discrepancies in chroma or hue (Awad, Stawarczyk, Liebermann, \& Ilie, 2015).

The obtained measurements can then be averaged for each respective combinatory group in order to holistically analyze each esthetic variable (Turgut \& Bagis, 2011). As a means to standardize, an obtained $\Delta \mathrm{E}_{\mathrm{ab}}^{*}$ value of 0 indicates a stable color match. $\mathrm{A} 0.5<\Delta \mathrm{E}_{\mathrm{ab}}^{*}>1.0$ is not considered to be clinically perceptible. A $1.0<\Delta \mathrm{E}^{*} \mathrm{ab}>2.0$ is regarded to be only clinically perceptible to $50 \%$ of observers, while a $\Delta \mathrm{E}^{*}{ }_{\mathrm{ab}}>3.7$ is considered as perceptible by all observers and clinically unacceptable (Bayindir \& Ozbayram, 2017; Yuan et al., 2007). However, other studies support a $\Delta \mathrm{E}_{\mathrm{ab}}^{*}>3.3$ as clinically unacceptable, so individual judgments must be made if a $\Delta \mathrm{E}^{*}$ ab value falls in between the discrepancy (Archegas, Freire, Vieira, Caldas, \& Souza, 2011; Knezovic, Zlataric, Illes, Alajbeg, \& Zagar, 2015).

\section{Luting Techniques}

The primary determinant of a natural tooth's color is the underlying dentin along with the translucency and thickness of the overlying enamel (O. Ozturk et al., 2008). Even so, the shade 
and thickness of the underlying cement, also referred to as a luting agent, can negatively influence the color parameters and shade matching of the ceramic restoration (de Azevedo Cubas, Camacho, Demarco, \& Pereira-Cenci, 2011; Marchionatti, Wandscher, May, Bottino, \& May, 2017; Niu et al., 2014; Omar, Atta, El-Mowafy, \& Khan, 2010; E. Ozturk et al., 2013). In order to properly prepare the ceramic to be luted using resin cements, its internal surface must first be treated to ensure sufficient surface roughness/texture and cleanliness. Mechanical methods of ceramic surface treatment include grinding, diamond abrasion, and airborne abrasion with aluminum oxide (Blatz, Sadan, \& Kern, 2003). No single method for surface-finishing has proven superior, but ultimately a decrease in surface smoothness can lead to a loss of translucency (Akar, Pekkan, Cal, Eskitascioglu, \& Ozcan, 2014). Hydrofluoric acid-etched ceramic restorations seated with resin cements have been shown to have higher success rates than those using zinc phosphate cements. This finding is believed to be due to both the micromechanical interlocking and chemical bonding between the two surfaces (Kelly, 2004), along with increased fracture resistance of both the ceramic and abutment tooth (Alqahtani, Aljurais, \& Alshaafi, 2012). Resin cements are made of similar components as resin composite restorations- an organic matrix (UDMA, TEGMA, Bis-GMA) coupled with inorganic fillers (Kelly, 2004).

The method of initiation helps differentiate resin cements from one another. Currently, these cements are available in auto-, light-, and dual-polymerizing systems (Marchionatti et al., 2017). Light-activated resin cements are traditionally designed for thinner all-ceramic restorations and offer longer handling times prior to a rapid hardening when cured (Archegas et al., 2011). Auto-polymerizing resin cements are commonly designed for bonding to metal or high-strength ceramics. Dual-activated, also known as dual-cure, resin cements can offer an 
extended working time and increased polymerization when light curing is supplemented (Kilinc, Antonson, Hardigan, \& Kesercioglu, 2011). However, when compared to light-cure resin cements, the dual-cure resin cements have been historically avoided in highly esthetic areas due to a greater tendency toward discoloring the margin and overall restoration. This finding can be linked to the traditional polymerizing activation mechanism that each system employs, and the environmental factors that can further contribute to the cement's discoloring effects.

(Marchionatti et al., 2017). These effects can become significant in esthetics cases when the ceramic thickness is less than $1.5 \mathrm{~mm}$ and the underlying tooth shade is noticeably dark (Dede, Ceylan, \& Yilmaz, 2017). One reasonable method in mitigating a darker abutment shade in the esthetic zone would be to use a ceramic core of medium or high opacity, further layered by veneering ceramic (Chaiyabutr, Kois, Lebeau, \& Nunokawa, 2011).

Study Purpose/Null Hypothesis

IPS e.max ceramics have excellent esthetic properties but unfortunately can adopt a grayish aspect after cementation, most likely due to their chemical composition, structure, and influencing factors from the substructure (Sen \& Us, 2017). Previous studies have examined the combined influences of thicknesses and translucencies on the ultimate color of all-ceramic restorations (Azer, Rosenstiel, Seghi, \& Johnston, 2011; Barizon et al., 2014; Kurklu, Azer, Yilmaz, \& Johnston, 2013; Wang, Takahashi, \& Iwasaki, 2013), but to the best of the author's knowledge, no study has yet analyzed the interactions of variable thickness and translucency on the final shade IPS e.max CAD overlaying a dark substrate (Awad et al., 2015; Bagis \& Turgut, 2013; Chaiyabutr et al., 2011). 
The purpose of this study is to gain an increased understanding of how combining minimal thickness and translucency affects the post-cementation shade of IPS e.max CAD ceramic restorations. Further insight on this subject could enhance the field of esthetic dentistry by better enabling practitioners to choose appropriate materials and/or techniques in order to better anticipate the final restorative shade after cementation on a dark substrate. A quantitative pattern could theoretically be observed between porcelain thickness and translucency when compared to a control. Analyzing this pattern could help provide a more predictable and concrete protocol for both clinicians and lab technicians. The first null hypothesis is that a statistically significant difference in the final shade of IPS e.max CADs will not be observed when variable thicknesses are applied. The second null hypothesis is that a statistically significant difference will not be observed in the final shade of IPS e.max CADs when translucency is increased. The third null hypothesis is that a statistically significant interaction will not be observed between thickness and translucency on the final shade. 


\section{CHAPTER 2}

\section{METHODS AND MATERIALS}

In this non-randomized control study, IPS e.max CAD shade A1 (IPS e.max, Ivoclar Vivadent AG, Schaan, Liechtenstein, Germany) samples were fabricated and recombined in such a way to individually assess each independent variable (thickness and translucency). Two impressions of an e.max CAD were taken using Polyvinyl Siloxane (Express STD, 3M ESPE, St Paul, MN, USA) to create molds with a $14.5 \mathrm{~mm}$ length and a $12.4 \mathrm{~mm}$ width, but one with a $0.3 \mathrm{~mm}$ thickness and another with a $1.5 \mathrm{~mm}$ thickness. A single light-cure, neutral shade resin cement sample (Ivoclar Variolink, Ivoclar Vivadent AG, Schaan, Liechtenstein) was made by applying the cement to the brim of the $0.3 \mathrm{~mm}$ thick PVS mold (Niu et al., 2014). An LED light (SmartLite, Dentsply, York, PA, USA) was used to cure the resin cement sample for 20 seconds at wavelength of $460 \mathrm{~nm}$ to ensure adequate polymerization. A single sample of shade $\mathrm{C} 4$ resin composite (Filtek Supreme, 3M ESPE, St Paul, MN, USA) was created by placing the composite in small increments to the brim of the $1.5 \mathrm{~mm}$ thick PVS mold and cured for 20 seconds using the same LED light. Each resin cement and resin composite sample were gently polished using 200-, 400-, and ultimately 600-grit sandpaper (All-Purpose, 3M ESPE, St Paul, MN, USA) in a cool water bath.

The IPS e.max CAD shade A1 porcelains were cut perpendicularly by means of a low speed diamond saw (Isomet, Bueher, Lake Buff, IL, USA) with a 0.6mm thick blade under 
copious amounts of water to produce 5 low translucency and 5 high translucency specimens at each of the 3 different thicknesses $(0.3 \mathrm{~mm}, 0.5 \mathrm{~mm}, 1.0 \mathrm{~mm})$. The same 200-, 400-, and 600-grit sandpaper was used under cool water to remove any sharp marginal edges and standardize the porcelain sample surfaces. In order to fabricate the control sample with the least chance of translucency interfering on the final shade, 5 IPS e.max CADs of low translucency and shade A1 were cut with the same diamond precision saw to remove the metal mandrel, thereby producing a 14.5mm thick sample. The porcelain CAD was then polished on the cut side using the 200, 400, and 600-grit sandpaper under cool water.

Per the manufacturer's instructions, an adequate amount of IPS Object Fix Flow (Ivoclar Vivadent AG, Schaan, Liechtenstein) was uniformly applied to the crystallization tray so that the porcelain samples did not come in direct contact with any metal surfaces. The porcelains were ordered on the tray in a way to appropriately maximize the number of samples undergoing each crystallization cycle. The tray was placed in the center of a ceramic furnace's (Programat EP 5000, Ivoclar Vivadent AG, Schaan, Liechtenstein) firing chamber in order to fully crystalize the samples using a pre-programmed setting specific to polished ceramics. Once the firing cycle was complete, the porcelains were carefully removed from the furnace and allowed to cool to room temperature. The residual Flow was removed and all porcelains were placed in the water bath for cleansing (Ivoclar Vivadent, 2012, February 1). All IPS e.max CAD, resin cement, and resin composite sample thicknesses were verified using a digital caliper (ProDent USA, East Brunswick, NJ, USA), and any specimen measuring $\pm 0.05 \mathrm{~mm}$ from the intended thickness was tolerated.

\section{Group Construction}


IPS e.max CAD specimens of low and high translucencies were further separated into three distinct sub-groups based on thickness (independent variables of $0.3 \mathrm{~mm}, 0.5 \mathrm{~mm}, 1.0 \mathrm{~mm}$ ), a width of $12.4 \mathrm{~mm}$, and a length of $14.5 \mathrm{~mm}$. Each porcelain specimen was stacked with the neutral shade resin cement and "dentin" composite shade C4 in order to form the groups listed in Figure 1. The samples were fastened together using a clear mylar strip with the edges taped to prevent any movement during the data acquisition. All sample groups were placed on a 1-inch glass slab under indoor, LED natural daylight conditions during sample testing.

\section{Sample Testing}

The Vita Easyshade (Vita Easyshade Advance 4.0, Yorba Linda, CA, USA) spectrophotometer (colorimeter) was used in this study to quantitatively evaluate the qualitative (color) nature of the groups. This spectrophotometer incorporates color filters that approximate the color spectrum, and in this case reflect data according to the CIEL*a*b* standards. It also provides a clinical 3D Vita shade, which incorporates 26 shades that homogenize colors along the chromatic spectrum. The value of a color is depicted by the first number, followed by the hue (letter), and ultimately the chroma (second number) (Gomez-Polo et al., 2017). Calibration of the Vita Easyshade was done by placing the probe tip into the calibration aperture prior to every obtained measurement (Kim-Pusateri et al., 2009). The Vita Easyshade proved to be the most accurate (92.6-93.75\%) out of a series of devices testing the reliability of colorimeters used both in-vitro and in-vivo (Dozic et al., 2007; Kim-Pusateri et al., 2009; Knezovic et al., 2015) The Vita Easyshade aperture was directed to the middle third of both the control and each combinatory group. Measurements were recorded 5 times for each combinatory group and the 5 control samples. Having 5 unique readings for each combinatory group provides added statistical 
reliability to the study. All obtained CIEL*a*b* data was hand recorded on a Microsoft Excel spreadsheet for future analysis.

Statistical Analysis

The color difference was measured and recorded by $\left(\Delta \mathrm{E}_{\mathrm{ab}}^{*}\right) \pm$ standard deviation for the 3 different thicknesses $(0.3 \mathrm{~mm}, 0.5 \mathrm{~mm}, 1.0 \mathrm{~mm})$ and 2 translucencies (low and high). Inferential statistical analysis of the data was evaluated using 2-way Factorial Analysis of Variance (ANOVA) $(\mathrm{p}<0.0001)$ to compare thickness and translucency, and a Tukey test $(\alpha=0.05)$ to evaluate within-group effects of translucency on the $\Delta \mathrm{E}^{*}$ ab at each variable thickness (SPSS version 23.0, SPSS, Chicago, IL, USA). 


\begin{tabular}{|c|c|c|c|}
\hline $\begin{array}{l}\text { Translucency } \\
\text { (LT/HT) }\end{array}$ & $\begin{array}{l}\text { IPS e.max } \\
\text { Thickness }\end{array}$ & $\begin{array}{c}\text { IPS e.max CAD } \\
\text { Shade }\end{array}$ & $\begin{array}{c}\text { Ivoclar Variolink Neutral } \\
\text { Shade Cement (N) }\end{array}$ \\
\hline & & (A1) & \\
\hline \multirow{3}{*}{ Low } & $0.3 \mathrm{~mm}$ & $(0.3 \mathrm{~mm}, \mathrm{~A} 1)$ & $(0.3 \mathrm{~mm}, \mathrm{~A} 1)$ \\
\hline & $0.5 \mathrm{~mm}$ & $(0.5 \mathrm{~mm}, \mathrm{~A} 1)$ & $(0.5 \mathrm{~mm}, \mathrm{~A} 1)$ \\
\hline & $1.0 \mathrm{~mm}$ & (1.0mm, A1) & $(1.0 \mathrm{~mm}, \mathrm{~A} 1)$ \\
\hline \multirow{3}{*}{ High } & $0.3 \mathrm{~mm}$ & $(0.3 \mathrm{~mm}, \mathrm{~A} 1)$ & $(0.3 \mathrm{~mm}, \mathrm{~A} 1)$ \\
\hline & $0.5 \mathrm{~mm}$ & $(0.5 \mathrm{~mm}, \mathrm{~A} 1)$ & $(0.5 \mathrm{~mm}, \mathrm{~A} 1)$ \\
\hline & $1.0 \mathrm{~mm}$ & $(1.0 \mathrm{~mm}, \mathrm{~A} 1)$ & $(1.0 \mathrm{~mm}, \mathrm{~A} 1)$ \\
\hline
\end{tabular}

Figure 1. The combinatory groups of IPS e.max CAD 


\section{CHAPTER 3}

\section{RESULTS}

The color difference $\left(\Delta \mathrm{E}^{*} \mathrm{ab}\right)$ and standard deviations (SD) of the 3 different thicknesses $(0.3 \mathrm{~mm}, 0.5 \mathrm{~mm}, 1.0 \mathrm{~mm})$ and 2 translucencies (low and high) were evaluated for IPS e.max CAD shade A1 overlaid on Variolink neutral shade resin cement and a C4 shade resin composite background. The CIEL*a*b* means and standard deviations obtained are listed in Figure 2. For a C4 underlying substrate, the final shades deviated from the shades of the control group, also listed in Figure 2. The means and standard deviations for $\Delta \mathrm{E}^{*} \mathrm{ab}$ are listed in Figure 3.

When comparing $0.3 \mathrm{~mm}, 0.5 \mathrm{~mm}, 1.0 \mathrm{~mm}$ thick IPS e.max CAD groups, a significant difference $(p<0.0001)$ was identified between the variable thicknesses, independent of the translucency level. The $0.3 \mathrm{~mm}$ porcelains displayed the largest mean $\Delta \mathrm{E}^{*}$ ab, followed by $0.5 \mathrm{~mm}$ and the $1.0 \mathrm{~mm}$, respectively.

When comparing the high and low translucency IPS e.max CAD groups, a significant difference $(\mathrm{p}<0.0001)$ was identified between the variable translucencies, independent of the thickness $(0.3 \mathrm{~mm}, 0.5 \mathrm{~mm}, 1.0 \mathrm{~mm})$. The mean $\Delta \mathrm{E}^{*}$ ab was the largest for the high translucency IPS e.max CAD groups.

When comparing the variables of minimal thickness and translucency to the observed $\Delta \mathrm{E}^{*}{ }_{\mathrm{ab}}$, a significant difference was identified among all groups, independent of the thickness or 
translucency ( $\mathrm{p}<0.0001)$. The 2-way ANOVA is illustrated in Figure 4 with standard error bars. For $\mathrm{LT}$ and $0.3 \mathrm{~mm}$ thick CADs, the final shades deviated to A3.5/3M2 as compared to the control's A1/1M1. For HT and $0.3 \mathrm{~mm}, 0.5 \mathrm{~mm}$ thick CADs, the final shades deviated to $\mathrm{C} 1 / 2 \mathrm{R} 1.5$ as compared to the control's A1/1M1. 


\begin{tabular}{|c|c|c|c|}
\hline Clinical Shade & $\begin{array}{l}\text { Vita Classic/ } \\
\text { Master-3D }\end{array}$ & CIELAB & $\mathbf{L} * \mathbf{a} * \mathbf{b} * \operatorname{Mean}(\mathbf{S D})$ \\
\hline Groups Low Trans. & & $\begin{array}{c}\text { Groups } \\
\text { Low } \\
\text { Trans. }\end{array}$ & \\
\hline$(\mathrm{C} 4,0.3, \mathrm{~A} 1, \mathrm{~N})$ & \multirow{2}{*}{$\begin{array}{l}\mathrm{A} 3.5 / 3 \mathrm{M} 2 \\
\mathrm{~A} 3.5 / 3 \mathrm{R} 2.5\end{array}$} & $\begin{array}{l}(\mathrm{C} 4,0.3 \\
\mathrm{A} 1, \mathrm{~N})\end{array}$ & \multirow{3}{*}{$\begin{array}{l}76.9(0.15) / 2.7(0.17) / 18.8(0.16) \\
76.6(0.11) / 2.9(0.11) / 17.7(0.09)\end{array}$} \\
\hline$(\mathrm{C} 4,0.5, \mathrm{~A} 1, \mathrm{~N})$ & & $\begin{array}{c}(\mathrm{C} 4,0.5 \\
\mathrm{A} 1, \mathrm{~N})\end{array}$ & \\
\hline$(\mathrm{C} 4,1.0, \mathrm{~A} 1, \mathrm{~N})$ & A $3.5 / 3 R 2.5$ & $\begin{array}{c}(\mathrm{C} 4,1.0 \\
\mathrm{A} 1, \mathrm{~N})\end{array}$ & \\
\hline (12x14x14- LT A1) & \multirow[t]{2}{*}{$\mathrm{A} 1 / 1 \mathrm{M} 1$} & $\begin{array}{l}(12 \times 14 \times 14- \\
\text { LT A1) }\end{array}$ & $\begin{array}{c}82.3(0.02) /- \\
2.9(0.07) / 11.5(0.02)\end{array}$ \\
\hline Groups High Trans. & & $\begin{array}{l}\text { Groups } \\
\text { High } \\
\text { Trans. }\end{array}$ & \\
\hline$(\mathrm{C} 4,0.3, \mathrm{~A} 1, \mathrm{~N})$ & $\mathrm{C} 1 / 2 \mathrm{R} 1.5$ & $\begin{array}{l}(\mathrm{C} 4,0.3 \\
\mathrm{A} 1, \mathrm{~N})\end{array}$ & \multirow{3}{*}{$\begin{array}{l}72.4(0.24) / 2.8(0.21) / 23.4(0.29) \\
74.5(0.09) / 2.9(0.16) / 25.2(0.21)\end{array}$} \\
\hline$(\mathrm{C} 4,0.5, \mathrm{~A} 1, \mathrm{~N})$ & \multirow{2}{*}{$\begin{array}{l}\mathrm{C} 1 / 2 \mathrm{R} 1.5 \\
\mathrm{D} 3 / 2 \mathrm{R} 1.5\end{array}$} & $\begin{array}{c}(\mathrm{C} 4,0.5 \\
\mathrm{A} 1, \mathrm{~N})\end{array}$ & \\
\hline$(\mathrm{C} 4,1.0, \mathrm{~A} 1, \mathrm{~N})$ & & $\begin{array}{c}(\mathrm{C} 4,1.0 \\
\mathrm{A} 1, \mathrm{~N})\end{array}$ & \\
\hline (12x14x14- LT A1) & $\mathrm{A} 1 / 1 \mathrm{M} 1$ & $\begin{array}{c}(12 \times 14 \times 14- \\
\text { LT A1) }\end{array}$ & $\begin{array}{c}82.3(0.02) /- \\
2.9(0.07) / 11.5(0.02)\end{array}$ \\
\hline
\end{tabular}

Figure 2. Observed color parameters and shades of IPS e.max CAD with variable translucency/thickness and control. 


\begin{tabular}{|c|c|c|c|c|c|}
\hline \multirow{2}{*}{\multicolumn{2}{|c|}{ Translucency $x$ Thickness }} & \multirow[b]{2}{*}{$\begin{array}{l}\text { Mean } \\
\Delta \mathbf{E}^{*}{ }_{a b}\end{array}$} & \multirow[b]{2}{*}{$\begin{array}{l}\text { Standard } \\
\text { Deviation }\end{array}$} & \multicolumn{2}{|c|}{$\begin{array}{l}\text { 95\% Confidence } \\
\text { Interval }\end{array}$} \\
\hline & & & & $\begin{array}{l}\text { Lower } \\
\text { Bound }\end{array}$ & $\begin{array}{l}\text { Upper } \\
\text { Bound }\end{array}$ \\
\hline \multirow{3}{*}{ HT } & .3 & 11.978 & .228 & 11.811 & 12.145 \\
\hline & .5 & 11.264 & 197 & 11.097 & 11.431 \\
\hline & 1.0 & 11.036 & .150 & 10.869 & 11.203 \\
\hline \multirow{3}{*}{ LT } & .3 & 9.178 & .270 & 9.011 & 9.345 \\
\hline & .5 & 9.046 & .049 & 8.879 & 9.213 \\
\hline & 1.0 & 8.480 & .084 & 8.313 & 8.647 \\
\hline
\end{tabular}

Figure 3. The difference in color means $\left(\Delta \mathrm{E}^{*}\right.$ ab) with standard deviation and upper/lower bounds of combined translucency and thickness of IPS e.max CAD 


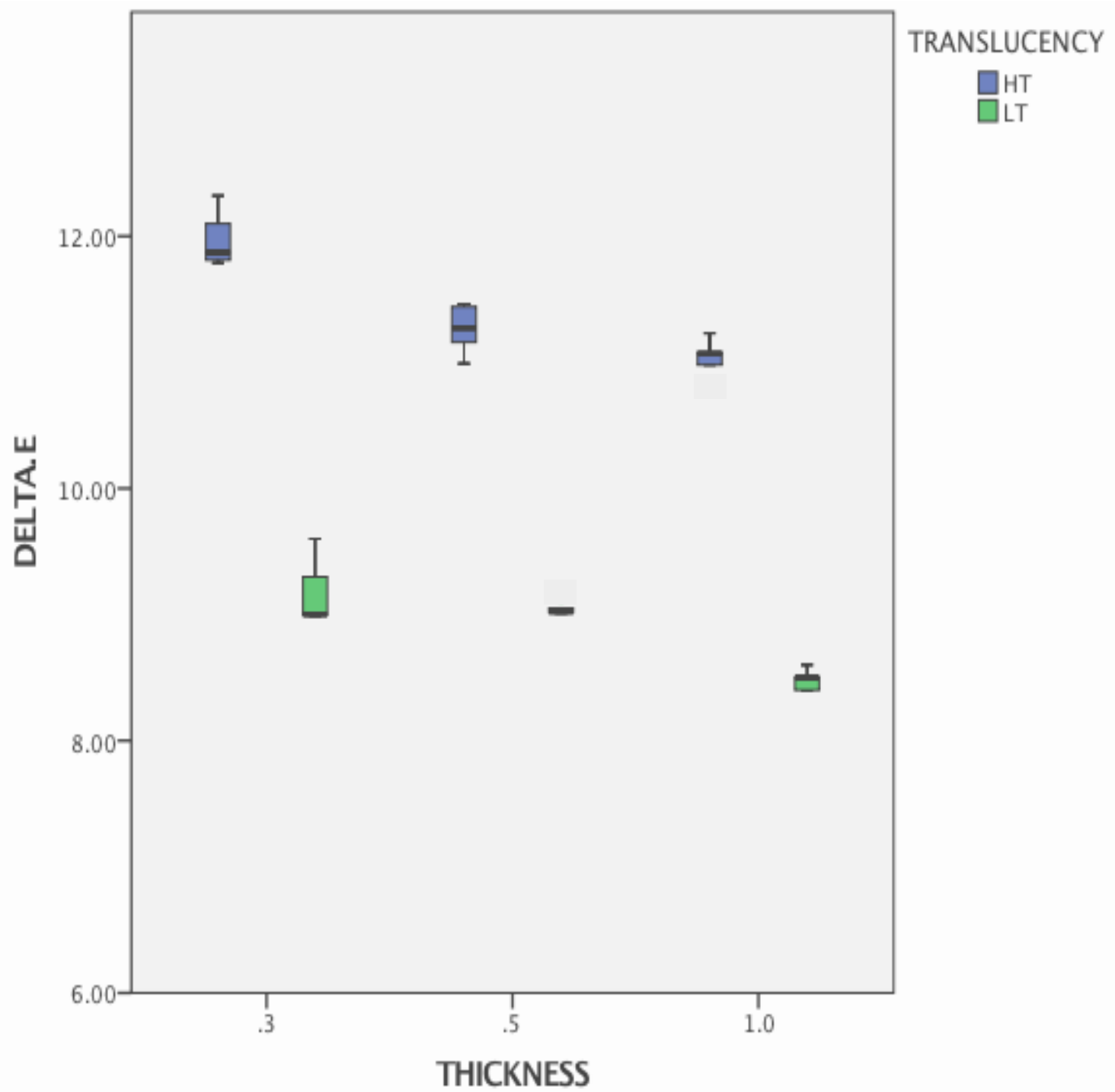

Figure 4. The difference in color means $\left(\Delta \mathrm{E}^{*} \mathrm{ab}\right)$ with standard error bars of combined translucency and thickness of IPS e.max CAD 


\section{CHAPTER 4}

\section{DISCUSSION}

Matching human teeth with ceramic restorations proves challenging since tooth appearance and shade are intricate processes. IPS e.max CAD was chosen as the test material due to its increasing popularity in all-ceramic restorations, even though there is still little information on its optical properties (Awad et al., 2015). All dental disciplines, especially restorative and prosthodontics, have felt the impact of CAD/CAM technologies. The methods and materials used in dentistry will continue to be influenced by what is deemed economical, efficient, and predictable (T. F. Alghazzawi, 2016). Therefore, it is feasible that the clinical application of IPS e.max CAD will be more widespread in the future, and a better understanding of its optical properties is imperative. In this study, the sample fabrication process became more streamlined by using IPS e.max CAD instead of IPS e.max Press because multiple porcelain specimens can be made from a single CAD. Otherwise, the financial costs would have been significantly higher since a single ingot would only produce a single Press specimen. The ceramic sample thicknesses were chosen according to what is clinically popular. Porcelain laminate veneers are commonly fabricated with thicknesses varying from $0.3 \mathrm{~mm}$ to roughly 1.0mm, depending on the clinical needs and desires (Azer et al., 2011). A resin composite shade C4 was used to simulate a darker, chromatic background (de Azevedo Cubas et al., 2011); the 
underlying abutment shade is more likely to cause a larger $\Delta \mathrm{E}$, thereby further challenging the independent variables (Chaiyabutr et al., 2011).

Considering the $\Delta \mathrm{E}^{*}$ ab of variable thickness IPS e.max CADs, the first null hypothesis was rejected. The results of this study show that as porcelain thickness is reduced from $1.0 \mathrm{~mm}$ to ultimately $0.3 \mathrm{~mm}$, a consistent increase in $\Delta \mathrm{E}^{*}$ ab becomes apparent, independent of the translucency level. Previous studies have been conducted on how thickness can affect the optical properties of all-ceramic systems (Begum et al., 2014; Chaiyabutr et al., 2011; de Azevedo Cubas et al., 2011; Dozic et al., 2003; W. Kang et al., 2018; Kurklu et al., 2013; Nakamura, Saito, Fuyikawa, \& Ishigaki, 2002; Niu et al., 2014; O. Ozturk et al., 2008; Pires, Novais, Araujo, \& Pegoraro, 2017; Sari et al., 2017; Sen \& Us, 2017; Silva et al., 2012; Vichi et al., 2011; Volpato, Monteiro, de Andrada, Fredel, \& Petter, 2009; Wang et al., 2013). Interestingly, Dozic et al. (2003) was able to demonstrate that a $0.70 \mathrm{~mm}$ ceramic core has the capability to mask a discoloring background under their layered specimens, which would otherwise display an increased $\Delta \mathrm{E}$. The combined works of Chaiyabutr et al. (2011); Volpato et al. (2009), and Nakamura et al. (2002) indicate that ceramic thicknesses $1.5 \mathrm{~mm}$ and greater are capable of masking dark substrates that would inherently lead to larger $\Delta \mathrm{E}$ values.

The optical properties of IPS e.max CAD are largely dependent on the porcelain thickness. As the thickness of a porcelain increases, the discoloring effects of the underlying dark substrate are lessened due to less light diffusion (Omar et al., 2010). A thicker material will display a larger refractive index, and ultimately a loss of translucency (Awad et al., 2015). Therefore, even minor changes in thickness should be seriously considered when applying highly translucent glass-ceramics in esthetic work. In previous studies, the $\Delta \mathrm{E}$ was significantly increased in test groups of $0.5 \mathrm{~mm}$ thicknesses compared to those of $1.0 \mathrm{~mm}$ (Turgut \& Bagis, 
2013). The observed opacity of a ceramic tends to increase with thicker restorations since most of the light diffusion and reflectance occurs in the ceramic itself; an opaquer ceramic should better mask the discoloring effects of a dark substructure (Sari et al., 2017). Restorations with a thickness of $0.3 \mathrm{~mm}$ are currently incapable of masking a substrate with a large color difference. In other words, if a lighter shade of porcelain is desired, the substrate shade must too be lightened in order to obtain a more acceptable $\Delta \mathrm{E}$, while the opposite is true for darker ultra-thin restorations (Comlekoglu et al., 2016; Sari et al., 2017).

Considering the $\Delta \mathrm{E}^{*}$ ab of increased translucency IPS e.max CADs, the second null hypothesis was rejected. The results of this study show that as the translucency level increases from low to high, a larger $\Delta \mathrm{E}^{*}$ ab becomes apparent, independent of the porcelain thickness. Previous studies have been conducted on how translucency can affect the optical properties of all-ceramic systems (Akar et al., 2014; Al Ben Ali, Kang, Finkelman, Zandparsa, \& Hirayama, 2014; Awad et al., 2015; Barizon et al., 2014; Harada et al., 2016; Heffernan et al., 2002; Johnston, 2014; Sen \& Us, 2017; Skyllouriotis, Yamamoto, \& Nathanson, 2017; Turgut et al., 2014; Vichi, Carrabba, Paravina, \& Ferrari, 2014; Vichi et al., 2011; Wang et al., 2013).

The optical properties of IPS e.max CAD are also largely dependent on the porcelain translucency. The level of a material's translucency can be viewed as the state between total transparency or opacity; therefore, a more translucent material diffuses more light instead of reflecting or absorbing it (Awad et al., 2015). As light passes through a ceramic material, microscopic filler particles and voids within the medium cause a scattering, and the amount of light that directly transmits is what the eyes perceives as the shade and overall appearance of the porcelain. It is imperative that the crystalline and glass matrix refractive indices are matched appropriately so that the translucency can be further controlled (Della Bona et al., 2014). Even 
though surface polishing is necessary, the translucency appears to be more dependent on the thickness and material itself (Wang et al., 2013), rather than the surface roughness. Therefore, the significantly high $\Delta \mathrm{E}^{*}$ ab values noted in both the low and high translucency porcelain combinations may be inherently contributed to material's composition. These findings can be further supported by the work of Wang et al. (2013) and Heffernan et al. (2002), who studied the effects of variable thickness on the observed porcelain translucency. The crystalline structure, porosity, pigments, grain size, and defects found within the porcelain could all influence the translucency (Awad et al., 2015). Even small granular imperfections can lead to a significant increase in opacity (Wang et al., 2013). Varying the heat treatments produces differences in crystalline composition and sizes (Della Bona et al., 2014). In the pre-crystalized state of high translucency CADs, there are only a few larger lithium metasilicate crystals. But in low translucency CADs, there are many small lithium metasilicate crystals (Al Ben Ali et al., 2014). After full crystallization, HT porcelains display crystals with a size of $1.5 \times 0.8 \mu \mathrm{m}$ interlocked in a low-density, glassy matrix, while LT porcelains are $0.8 \mathrm{x} 0.2 \mu \mathrm{m}$ within a high-density, glassy matrix (Della Bona et al., 2014).

Previous studies done on lithium disilicate systems such as IPS e.max Press and IPS e.max CAD have demonstrated no significant differences in $\mathrm{L}^{*} \mathrm{a} \mathrm{b}^{*}$, translucency, or chroma, even though the two systems have markedly different processing techniques (Giordano \& McLaren, 2010). These studies have shown that machinable and pressable systems possess a greater resistance to fracture than their traditional powder/liquid counterparts, along with maintaining enhanced esthetics for anterior veneer and crown restorations (Giordano \& McLaren, 2010). These findings can be contributed to an increase in fabrication reliability; CAD/CAM and heat-pressed methods reduce the amount of early stage defects and large 
porosities (Della Bona, Pecho, Ghinea, Cardona, \& Perez, 2015). Therefore, the optical qualities of the IPS e.max are more likely dependent on the crystalline content rather than the method of construction. Visible light has a wavelength spectrum of roughly 400-700nm, and should the crystals be smaller than this range, the porcelain will have a transparent appearance. Conversely, crystals larger than this range will be opaque due to light being reflected diffusely and scattering internally (Awad et al., 2015; Bagis \& Turgut, 2013). 


\section{CONCLUSIONS}

Within the limitations of this in-vitro study, the following conclusions were derived:

1.) As the thickness of IPS e.max CAD is decreased, the likelihood of an observed final shade change $(\Delta \mathrm{E})$ increases, especially when the porcelain overlays a discolored substrate.

2.) As the translucency of IPS e.max CAD is decreased, the likelihood of an observed final shade change $(\Delta \mathrm{E})$ decreases, especially when the porcelain overlays a discolored substrate.

3.) Clinicians who understand optics, color, dental materials, and effective ways to communicate with their dental technicians will experience higher levels of success than those who do not. 


\section{FUTURE DIRECTIONS}

This present study contains limitations that should be expanded on in future studies. The results obtained pertain to the specific ceramic and luting materials utilized and similar products may produce different outcomes. Ensuring that the measurements are taken under CIE Standard Illuminant D65 may also provide different results (Pecho, Perez, Ghinea, \& Della Bona, 2016). The porcelain samples were heat-treated only 1 time using the manufacturer's recommendation. Previous studies demonstrate the discoloring effects that multiples firings can have on allceramic systems (O. Ozturk et al., 2008). By increasing the number or firings and/or the firing temperature, the color pigments located within the porcelain may become distorted and unstable, thereby leading to an unintended color change (Bayindir \& Ozbayram, 2017). Implementing the same methods but with repeated firings could lead to varying results in a future study. Niu et al. (2014) did a pilot study using immersion oil to connect each sample but found no effect on the observed color. Our technique allowed us to simply stack the samples into their respective groups but connecting them with immersion oil may produce different results.

Additionally, a study done by Dede et al. (2017) showed that both the resin cement shade and brand are significant for color differences. In their experiment comparing the $\Delta \mathrm{E} 00$ of different resin cement types, only the Variolink translucent shade proved to have a $\Delta \mathrm{E}_{00}$ that was

clinically unacceptable. The reasons behind this finding may extend to our Variolink neutral shade and using an alternative resin cement brand in future studies may possibly produce different results. Also, using spectrophotometers to measure tooth color can be disadvantageous 
due to its inherent design for measuring flat surfaces, while most clinical surfaces have at least some degree of curvature (Park et al., 2006). Fabricating porcelain specimens in the anatomical shape of a crown could provide differing results when utilizing colorimeters/spectrophotometers. 


\section{REFERENCES}

Ahn, J. S., \& Lee, Y. K. (2008). Color distribution of a shade guide in the value, chroma, and hue scale. Journal of Prosthetic Dentistry, 100(1), 18-28. doi:10.1016/S00223913(08)60129-8

Akar, G. C., Pekkan, G., Cal, E., Eskitascioglu, G., \& Ozcan, M. (2014). Effects of surfacefinishing protocols on the roughness, color change, and translucency of different ceramic systems. Journal of Prosthetic Dentistry, 112(2), 314-321. doi:10.1016/j.prosdent.2013.09.033

Al Ben Ali, A., Kang, K., Finkelman, M. D., Zandparsa, R., \& Hirayama, H. (2014). The effect of variations in translucency and background on color differences in CAD/CAM lithium disilicate glass ceramics. Journal of Prosthodontics, 23(3), 213-220. doi:10.1111/jopr.12080

Alghazzawi, T. F. (2016). Advancements in CAD/CAM technology: Options for practical implementation. Journal of Prosthodontic Research, 60(2), 72-84. doi:10.1016/j.jpor.2016.01.003

Alghazzawi, T. F., Lemons, J., Liu, P.-R., Essig, M. E., \& Janowski, G. M. (2012). The failure load of CAD/CAM generated zirconia and glass-ceramic laminate veneers with different preparation designs. The Journal of Prosthetic Dentistry, 108(6), 386-393. doi:10.1016/s0022-3913(12)60198-X

Alkadi, L., \& Ruse, N. D. (2016). Fracture toughness of two lithium disilicate dental glass ceramics. Journal of Prosthetic Dentistry. doi:10.1016/j.prosdent.2016.02.009 
Alqahtani, M. Q., Aljurais, R. M., \& Alshaafi, M. M. (2012). The effects of different shades of resin luting cement on the color of ceramic veneers. Dental Materials Journal, 31(3), 354-361.

Archegas, L. R., Freire, A., Vieira, S., Caldas, D. B., \& Souza, E. M. (2011). Colour stability and opacity of resin cements and flowable composites for ceramic veneer luting after accelerated ageing. Journal of Dentistry, 39(11), 804-810.

doi:10.1016/j.jdent.2011.08.013

Awad, D., Stawarczyk, B., Liebermann, A., \& Ilie, N. (2015). Translucency of esthetic dental restorative $\mathrm{CAD} / \mathrm{CAM}$ materials and composite resins with respect to thickness and surface roughness. Journal of Prosthetic Dentistry, 113(6), 534-540.

doi:10.1016/j.prosdent.2014.12.003

Azer, S. S., Rosenstiel, S. F., Seghi, R. R., \& Johnston, W. M. (2011). Effect of substrate shades on the color of ceramic laminate veneers. Journal of Prosthetic Dentistry, 106(3), 179183. doi:10.1016/S0022-3913(11)60117-0

Bagis, B., \& Turgut, S. (2013). Optical properties of current ceramics systems for laminate veneers. Journal of Dentistry, 41 Suppl 3, e24-30. doi:10.1016/j.jdent.2012.11.013

Barizon, K. T., Bergeron, C., Vargas, M. A., Qian, F., Cobb, D. S., Gratton, D. G., \& Geraldeli, S. (2014). Ceramic materials for porcelain veneers: part II. Effect of material, shade, and thickness on translucency. Journal of Prosthetic Dentistry, 112(4), 864-870. doi:10.1016/j.prosdent.2014.05.016

Bayindir, F., \& Ozbayram, O. (2017). Effect of number of firings on the color and translucency of ceramic core materials with veneer ceramic of different thicknesses. Journal of Prosthetic Dentistry. doi:10.1016/j.prosdent.2017.02.011 
Begum, Z., Chheda, P., Shruthi, C. S., \& Sonika, R. (2014). Effect of ceramic thickness and luting agent shade on the color masking ability of laminate veneers. Journal of the Indian Prosthodontic Society, 14(Suppl 1), 46-50. doi:10.1007/s13191-014-0362-2

Beier, U. S., Kapferer, I., Burtscher, D., \& Dumfahrt, H. (2012). Clinical performance of porcelain laminate veneers for up to 20 years. International Journal of Prosthodontics, 25(1), 79-85.

Blatz, M. B., Sadan, A., \& Kern, M. (2003). Resin-ceramic bonding: a review of the literature. Journal of Prosthetic Dentistry, 89(3), 268-274. doi:10.1067/mpr.2003.50

Calamia, J. R. (1983). Etched porcelain facial veneers: a new treatment modality based on scientific and clinical evidence. New York Journal of Dentistry, 53(6), 255-259.

Chaiyabutr, Y., Kois, J. C., Lebeau, D., \& Nunokawa, G. (2011). Effect of abutment tooth color, cement color, and ceramic thickness on the resulting optical color of a CAD/CAM glassceramic lithium disilicate-reinforced crown. Journal of Prosthetic Dentistry, 105(2), 8390. doi:10.1016/S0022-3913(11)60004-8

Comlekoglu, M. E., Paken, G., Tan, F., Dundar-Comlekoglu, M., Ozcan, M., Akan, E., \& Aladag, A. (2016). Evaluation of different thickness, die color, and resin cement shade for veneers of multilayered CAD/CAM blocks. Journal of Prosthodontics, 25(7), 563569. doi:10.1111/jopr.12367

da Cunha, L. F., Mukai, E., Hamerschmitt, R. M., \& Correr, G. M. (2015). Fabrication of lithium silicate ceramic veneers with a CAD/CAM approach: a clinical report of cleidocranial dysplasia. Journal of Prosthetic Dentistry, 113(5), 355-359.

doi:10.1016/j.prosdent.2014.10.004 
da Cunha, L. F., Reis, R., Santana, L., Romanini, J. C., Carvalho, R. M., \& Furuse, A. Y. (2013). Ceramic veneers with minimum preparation. European Journal of Dentistry, 7(4), 492496. doi:10.4103/1305-7456.120645

de Azevedo Cubas, G. B., Camacho, G. B., Demarco, F. F., \& Pereira-Cenci, T. (2011). The effect of luting agents and ceramic thickness on the color variation of different ceramics against a chromatic background. European Journal of Dentistry, 5(3), 245-252.

Dede, D. O., Ceylan, G., \& Yilmaz, B. (2017). Effect of brand and shade of resin cements on the final color of lithium disilicate ceramic. Journal of Prosthetic Dentistry, 117(4), 539-544. doi:10.1016/j.prosdent.2016.07.014

Della Bona, A., Nogueira, A. D., \& Pecho, O. E. (2014). Optical properties of CAD-CAM ceramic systems. Journal of Dentistry, 42(9), 1202-1209. doi:10.1016/j.jdent.2014.07.005

Della Bona, A., Pecho, O. E., Ghinea, R., Cardona, J. C., \& Perez, M. M. (2015). Colour parameters and shade correspondence of CAD-CAM ceramic systems. Journal of Dentistry, 43(6), 726-734. doi:10.1016/j.jdent.2015.02.015

Dozic, A., Kleverlaan, C. J., El-Zohairy, A., Feilzer, A. J., \& Khashayar, G. (2007). Performance of five commercially available tooth color-measuring devices. Journal of Prosthodontics, 16(2), 93-100. doi:10.1111/j.1532-849X.2007.00163.x

Dozic, A., Kleverlaan, C. J., Meegdes, M., van der Zel, J., \& Feilzer, A. J. (2003). The influence of porcelain layer thickness on the final shade of ceramic restorations. Journal of Prosthetic Dentistry, 90(6), 563-570. doi:10.1016/S0022391303005171 
Dozic, A., Tsagkari, M., Khashayar, G., \& Aboushelib, M. (2010). Color management of porcelain veneers: influence of dentin and resin cement colors. Quintessence International, 41(7), 567-573.

Friedman, M. J. (2001). Masters of esthetic dentistry. Journal of Esthetic and Restorative Dentistry, 13, 318-327. doi:10.1111/j.1708-8240.2001.tb01014.x

Giordano, R., \& McLaren, E. A. (2010). Ceramics overview: classification by microstructure and processing methods. Compendium of Continuing Education in Dentistry, 31(9), 682-684, 686, 688 passim; quiz 698, 700 .

Gomez-Polo, C., Gomez-Polo, M., Martinez Vazquez de Parga, J. A., \& Celemin-Vinuela, A. (2017). Clinical study of the 3D-Master color system among the Spanish population. Journal of Prosthodontics. doi:10.1111/jopr.12584

Gomez-Polo, C., Portillo Munoz, M., Lorenzo Luengo, M. C., Vicente, P., Galindo, P., \& Martin Casado, A. M. (2016). Comparison of the CIELab and CIEDE2000 color difference formulas. Journal of Prosthetic Dentistry, 115(1), 65-70. doi:10.1016/j.prosdent.2015.07.001

Goujat, A., Abouelleil, H., Colon, P., Jeannin, C., Pradelle, N., Seux, D., \& Grosgogeat, B. (2018). Mechanical properties and internal fit of 4 CAD-CAM block materials. Journal of Prosthetic Dentistry, 119(3), 384-389. doi:10.1016/j.prosdent.2017.03.001

Harada, K., Raigrodski, A. J., Chung, K. H., Flinn, B. D., Dogan, S., \& Mancl, L. A. (2016). A comparative evaluation of the translucency of zirconias and lithium disilicate for monolithic restorations. Journal of Prosthetic Dentistry. doi:10.1016/j.prosdent.2015.11.019 
Heffernan, M. J., Aquilino, S. A., Diaz-Arnold, A. M., Haselton, D. R., Stanford, C. M., \& Vargas, M. A. (2002). Relative translucency of six all-ceramic systems. Part II: core and veneer materials. Journal of Prosthetic Dentistry, 88(1), 10-15.

Horn, H. R. (1983). A new lamination: porcelain bonded to enamel. New York State Dental Journal, 49(6), 401-403.

Ishikawa-Nagai, S., Yoshida, A., Sakai, M., Kristiansen, J., \& Da Silva, J. D. (2009). Clinical evaluation of perceptibility of color differences between natural teeth and all-ceramic crowns. Journal of Dentistry, 37 Suppl 1, e57-63. doi:10.1016/j.jdent.2009.04.004

Ivoclar Vivadent. (2012, February 1). EP 5000 G2. Retrieved from https://www.ivoclarvivadent.com/zoolu-website/media/.../Programat+EP5000-G2

Ivoclar Vivadent. (2015, October). IPS e.max CAD Monolithic Solutions CHAIRSIDE. Retrieved from https://www.ivoclarvivadent.us/mam/celum/celum_assets/8937023045662_IPS_emax_CAD_Monolithic_Solutions_Chairside_pdf_4774.pdf?3

Ivoclar Vivadent. (2017). IPS e.max CAD. Retrieved from https://www.ivoclarvivadent.us/explore/ips-emax-cad-blocks

Johnston, W. M. (2014). Review of translucency determinations and applications to dental materials. Journal of Esthetic Restorative Dentistry, 26(4), 217-223. doi:10.1111/jerd.12112

Kang, S., Chang, J., \& Son, H. H. (2013). Flexural strength and microstructure of two lithium disilicate glass ceramics for CAD/CAM restoration in the dental clinic. Restorative Dental Endodontics, 38(3), 134-140. doi:10.5395/rde.2013.38.3.134 
Kang, W., Park, J. K., Kim, S. R., Kim, W. C., \& Kim, J. H. (2018). Effects of core and veneer thicknesses on the color of CAD-CAM lithium disilicate ceramics. Journal of Prosthetic Dentistry, 119(3), 461-466. doi:10.1016/j.prosdent.2017.04.005

Kelly, J. R. (2004). Dental ceramics: current thinking and trends. Dental Clinics of North America, 48(2), viii, 513-530. doi:10.1016/j.cden.2004.01.003

Kilinc, E., Antonson, S. A., Hardigan, P. C., \& Kesercioglu, A. (2011). The effect of ceramic restoration shade and thickness on the polymerization of light- and dual-cure resin cements. Operative Dentistry, 36(6), 661-669. doi:10.2341/10-206-L

Kim-Pusateri, S., Brewer, J. D., Davis, E. L., \& Wee, A. G. (2009). Reliability and accuracy of four dental shade-matching devices. Journal of Prosthetic Dentistry, 101(3), 193-199. doi:10.1016/s0022-3913(09)60028-7

Knezovic, D., Zlataric, D., Illes, I. Z., Alajbeg, M., \& Zagar. (2015). In vivo and in vitro evaluations of repeatability and accuracy of VITA Easyshade(R) Advance 4.0 dental shade-matching device. Acta Stomatologica Croatica, 49(2), 112-118. doi:10.15644/asc49/2/4

Kurklu, D., Azer, S. S., Yilmaz, B., \& Johnston, W. M. (2013). Porcelain thickness and cement shade effects on the colour and translucency of porcelain veneering materials. Journal of Dentistry, 41(11), 1043-1050. doi:10.1016/j.jdent.2013.08.017

Leempoel, P. J., Eschen, S., De Haan, A. F., \& Van't Hof, M. A. (1985). An evaluation of crowns and bridges in a general dental practice. Journal of Oral Rehabilitation, 12(6), 515-528.

Marchionatti, A. M. E., Wandscher, V. F., May, M. M., Bottino, M. A., \& May, L. G. (2017). Color stability of ceramic laminate veneers cemented with light-polymerizing and dual- 
polymerizing luting agent: A split-mouth randomized clinical trial. Journal of Prosthetic Dentistry, 118(5), 604-610. doi:10.1016/j.prosdent.2016.11.013

McLean, J. W. (1967). The alumina reinforced porcelain jacket crown. Journal of the American Dental Association, 75(3), 621-628.

Nakamura, T., Saito, O., Fuyikawa, J., \& Ishigaki, S. (2002). Influence of abutment substrate and ceramic thickness on the colour of heat-pressed ceramic crowns. Journal of Oral Rehabilitation, 29(9), 805-809.

Niu, E., Agustin, M., \& Douglas, R. D. (2014). Color match of machinable lithium disilicate ceramics: Effects of cement color and thickness. Journal of Prosthetic Dentistry, 111(1), 42-50. doi:10.1016/j.prosdent.2013.09.005

Omar, H., Atta, O., El-Mowafy, O., \& Khan, S. A. (2010). Effect of CAD-CAM porcelain veneers thickness on their cemented color. Journal of Dentistry, 38 Suppl 2, e95-99. doi:10.1016/j.jdent.2010.05.006

Ozturk, E., Chiang, Y. C., Cosgun, E., Bolay, S., Hickel, R., \& Ilie, N. (2013). Effect of resin shades on opacity of ceramic veneers and polymerization efficiency through ceramics. Journal of Dentistry, 41 Suppl 5, e8-14. doi:10.1016/j.jdent.2013.06.001

Ozturk, O., Uludag, B., Usumez, A., Sahin, V., \& Celik, G. (2008). The effect of ceramic thickness and number of firings on the color of two all-ceramic systems. Journal of Prosthetic Dentistry, 100(2), 99-106. doi:10.1016/s0022-3913(08)60156-0

Park, J. H., Lee, Y. K., \& Lim, B. S. (2006). Influence of illuminants on the color distribution of shade guides. Journal of Prosthetic Dentistry, 96(6), 402-411. doi:10.1016/j.prosdent.2006.10.007 
Pecho, O. E., Ghinea, R., Alessandretti, R., Perez, M. M., \& Della Bona, A. (2016). Visual and instrumental shade matching using CIELAB and CIEDE2000 color difference formulas. Dental Materials, 32(1), 82-92. doi:10.1016/j.dental.2015.10.015

Pecho, O. E., Perez, M. M., Ghinea, R., \& Della Bona, A. (2016). Lightness, chroma and hue differences on visual shade matching. Dental Materials, 32(11), 1362-1373. doi:10.1016/j.dental.2016.08.218

Peumans, M., Van Meerbeek, B., Lambrechts, P., \& Vanherle, G. (2000). Porcelain veneers: a review of the literature. Journal of Dentistry, 28(3), 163-177.

Pires, L. A., Novais, P. M., Araujo, V. D., \& Pegoraro, L. F. (2017). Effects of the type and thickness of ceramic, substrate, and cement on the optical color of a lithium disilicate ceramic. Journal of Prosthetic Dentistry, 117(1), 144-149. doi:10.1016/j.prosdent.2016.04.003

Pospiech, P. (2002). All-ceramic crowns: bonding or cementing? Clinical Oral Investigations, 6(4), 189-197. doi:10.1007/s00784-002-0183-2

Sari, T., Ural, C., Yuzbasioglu, E., Duran, I., Cengiz, S., \& Kavut, I. (2017). Color match of a feldspathic ceramic CAD-CAM material for ultrathin laminate veneers as a function of substrate shade, restoration color, and thickness. Journal of Prosthetic Dentistry. doi:10.1016/j.prosdent.2017.02.022

Schmitter, M., \& Seydler B, B. (2012). Minimally invasive lithium disilicate ceramic veneers fabricated using chairside CAD/CAM: A clinical report. The Journal of Prosthetic Dentistry, 107(2), 71-74. doi:10.1016/s0022-3913(12)00012-1

Sen, N., \& Us, Y. O. (2017). Mechanical and optical properties of monolithic CAD-CAM restorative materials. Journal of Prosthetic Dentistry. doi:10.1016/j.prosdent.2017.06.012 
Shenoy, A., \& Shenoy, N. (2010). Dental ceramics: An update. Journal of Conservative Dentistry, 13(4), 195-203. doi:10.4103/0972-0707.73379

Silva, N. R., Bonfante, E. A., Martins, L. M., Valverde, G. B., Thompson, V. P., Ferencz, J. L., \& Coelho, P. G. (2012). Reliability of reduced-thickness and thinly veneered lithium disilicate crowns. Journal of Dental Research, 91(3), 305-310. doi:10.1177/0022034511433504

Simonsen RJ., \& Calamia JR. (1983). Tensile bond strengths of etched porcelain. Journal of Dental Research, 62(Abstract 1099).

Skyllouriotis, A. L., Yamamoto, H. L., \& Nathanson, D. (2017). Masking properties of ceramics for veneer restorations. Journal of Prosthetic Dentistry. doi:10.1016/j.prosdent.2016.12.003

Turgut, S., \& Bagis, B. (2011). Colour stability of laminate veneers: an in vitro study. Journal of Dentistry, 39 Suppl 3, e57-64. doi:10.1016/j.jdent.2011.11.006

Turgut, S., \& Bagis, B. (2013). Effect of resin cement and ceramic thickness on final color of laminate veneers: an in vitro study. Journal of Prosthetic Dentistry, 109(3), 179-186. doi:10.1016/S0022-3913(13)60039-6

Turgut, S., Bagis, B., Ayaz, E. A., Korkmaz, F. M., Ulusoy, K. U., \& Bagis, Y. H. (2014). How will surface treatments affect the translucency of porcelain laminate veneers? Journal of Advanced Prosthodontics, 6(1), 8-13. doi:10.4047/jap.2014.6.1.8

Uludag, B., Usumez, A., Sahin, V., Eser, K., \& Ercoban, E. (2007). The effect of ceramic thickness and number of firings on the color of ceramic systems: an in vitro study. Journal of Prosthetic Dentistry, 97(1), 25-31. doi:10.1016/j.prosdent.2006.11.002 
Vafiadis, D., \& Goldstein, G. (2011). Single visit fabrication of a porcelain laminate veneer with CAD/CAM technology: A clinical report. The Journal of Prosthetic Dentistry, 106(2), 71-73. doi:10.1016/s0022-3913(11)00100-4

Vichi, A., Carrabba, M., Paravina, R., \& Ferrari, M. (2014). Translucency of ceramic materials for CEREC CAD/CAM system. Journal of Esthetic Restorative Dentistry, 26(4), 224231. doi:10.1111/jerd.12105

Vichi, A., Louca, C., Corciolani, G., \& Ferrari, M. (2011). Color related to ceramic and zirconia restorations: a review. Dental Materials, 27(1), 97-108. doi:10.1016/j.dental.2010.10.018

Volpato, C. A., Monteiro, S., Jr., de Andrada, M. C., Fredel, M. C., \& Petter, C. O. (2009). Optical influence of the type of illuminant, substrates and thickness of ceramic materials. Dental Materials, 25(1), 87-93. doi:10.1016/j.dental.2008.04.013

Wang, F., Takahashi, H., \& Iwasaki, N. (2013). Translucency of dental ceramics with different thicknesses. Journal of Prosthetic Dentistry, 110(1), 14-20. doi:10.1016/S00223913(13)60333-9

Yuan, J. C., Brewer, J. D., Monaco, E. A., Jr., \& Davis, E. L. (2007). Defining a natural tooth color space based on a 3-dimensional shade system. Journal of Prosthetic Dentistry, 98(2), 110-119. doi:10.1016/S0022-3913(07)60044-4 


\section{CURRICULUM VITA}

NAME: Peter F. Alena

ADDRESS: 925 Ardmore Drive

Louisville, KY 40217

DOB: 01/09/1991

EDUCATION \& TRAINING:

Bachelor of Science in Microbiology

University of Georgia

2009-2013

Candidate, Doctor of Dental Medicine

Candidate, Master of Science in Oral Biology

University of Louis ville School of Dentistry

2014-2018

AWARDS:

ULSD Summer Research Fellowship, 2015

ULSD Summer Research Fellowship, 2016 